\title{
High-level stakeholders' insights on readying Australia for Next Generation Broadband
}

\author{
Claire Mason \\ CSIRO \\ Beth O’Brien-McInally \\ Department of Education, Training, and Employment, Queensland \\ Sharon Dane \\ CSIRO
}

Summary: We interviewed 24 high-level representatives from across Australian society and industry to explore (a) what changes might occur in each sector once next generation broadband (NGB) is widely available and (b) what action is needed to prepare for these changes. Most participants expected NGB to have a positive and profound effect on business and daily life in Australia. However, Australian organisations had been slow to engage with the opportunities offered by NGB. They were also concerned that certain groups could get left behind through digital divide. They called for government to better articulate the role of NGB in supporting Australia's future social and economic prosperity, to act as a front-runner in the use of the new technology and to deliver policy addressing barriers to uptake. Leadership was also needed from public and private organisations, both to build the nation's digital capability and in utilising NGB to transform business processes. 


\section{Introduction}

This paper provides much needed insight into the potential impacts and challenges associated with Next Generation Broadband (NGB) in Australia. Australia's investment in NGB infrastructure is informed by research suggesting that high capacity networks can support human development and economic growth (Benkler et al. 2010, Budde 2013, Gans and King 2010). However, international experiences with NGB reveal considerable variation in terms of uptake and engagement with NGB (Aizu 2002, Benkler et al. 2010, Frieden 2005, Lau, Kim, and Atkin 2005, Lee and Chan-Olmsted 2004). It seems that, as with other technological innovations, the outcomes derived from next generation broadband depend on a range of factors, including the readiness of end-users to engage with it. This research provides rich data, namely insight from leaders and experts from across Australian society and industry, as to the opportunities and risks associated with NGB in Australia, and the actions that need to be taken to ensure that we maximise the benefits derived from this infrastructure.

Next generation broadband is often described as a 'disruptive innovation,' in that it is seen to have the potential to transform business models, change the relationships among stakeholders, create new services, demand new skill sets and outmode existing industries (Middleton, Park, and Allen 2013). Although some of the impacts associated with a disruptive innovation may be difficult to predict, there is value in attempting to identify and prepare for these changes ahead of time, simply because change (developing new skills, reengineering organisational processes) takes time and effort, and failure to do so can have very negative impacts. However, as the effects of next generation broadband may play out differently for different groups and different sectors, we need not only to understand what applications NGB can enable, but also how they might be applied in each sector and usergroup. Thus, to prepare for NGB, we need to bring together an understanding of the technology, and an understanding of the different contexts in which the technology will be experienced. The purpose of this study, then, was to capture this information by interviewing high-level representatives from across the different stakeholder groups for NGB in Australia.

While the specifications assigned to the term 'next generation broadband' vary, it usually refers to data telecommunications systems that have scalable bandwidth (generally capable of at least 25Mbps downstream), symmetric capability (meaning upstream bandwidths are close to or equal to downstream bandwidths), support services of different quality levels, and are ubiquitous in terms of coverage. The NGB network planned for Australia is comparable with NGB networks that have been implemented in (or are planned for) other countries around the world. Thus, research in those countries where NGB is already available provides an important source of information about the types of impacts 
that are experienced from next generation broadband and how to prepare for them.

However, it is also important to consider how these effects are likely to play out in Australia's unique social, economic and geographic environment. Thus, our analysis begins with a review of international experiences with NGB and an overview of Internet use in Australia. We then go on to describe the process that we followed and the findings that we obtained from our interviews with stakeholder group representatives.

\section{Learning from international experiences with NGB}

International ranking systems (e.g., International Telecommunication Union 2013b, OECD 2013, World Bank 2013) comparing broadband uptake across countries show that uptake does not follow automatically or uniformly with the provision of broadband, or more specifically, NGB. Economic and demographic factors (economic prosperity, income, education, computer penetration age and population density) explain much of the variation in broadband adoption (Beard et al. 2010, Jakopin and Klein 2011). However, global leadership in NGB requires other attributes. The Republic of Korea is generally identified as the global leader for broadband deployment (International Telecommunication Union 2013a, Lee and Chan-Olmsted 2004). In Korea, the provision of NGB infrastructure was accompanied by demand-side management strategies, including services, applications and demand promotion policies (Katz 2012). However, analysts attribute the success of NGB in Korea to a confluence of factors, including the political situation, geographic factors, people's mentality and the cultural context (Aizu 2002). Thus, the recipe for achieving high uptake of NGB is likely to be complex and unique to each country.

However, achieving high uptake is just the starting point for successful utilization of NGB. We also need to consider the impacts that are experienced from its deployment. The new technologies enabled by NGB are expected to result in substantial cost efficiencies and improvements in the delivery of health (INSEAD and World Economic Forum 2013, National Broadband Task Force 2001), education (National Broadband Task Force 2001) and government services (Bauer et al. 2002, House of Representatives Standing Committee on Infrastructure and Communications 2011). Furthermore, the impact of increased digitisation varies across nations, sectors and social groups. For example, broadband can improve employment in developing economies but lead to reductions in employment in advanced-stage economies as lower-value-added, labour-intensive jobs go overseas where labour is cheaper (INSEAD and World Economic Forum 2013). Other research has found that broadband has a stronger effect on productivity in sectors with high transaction costs and high labour intensity (International Telecommunication Union 2013b). In addition, since the uptake of digital technology tends to be lower amongst disadvantaged groups, 
increased digitization may serve to exacerbate existing social inequalities, (Baum, Locke, and Kirkpatrick 1998, Helsper, Dutton, and Gerber 2008).

The level of Internet use in Australia is currently only slightly below that of most other developed countries (International Telecommunication Union 2013b). However, Australia ranks relatively low in terms of affordability of access to ICT infrastructure (INSEAD and World Economic Forum 2013). The Australian Bureau of Statistics reports that in 2012-2013, 17\% of Australians aged 15 and older had not accessed the Internet in the past year (Australian Bureau of Statistics 2014) and although nine in very ten Australian businesses have Internet access, only $45 \%$ have a presence on the web (Australian Bureau of Statistics 2013). Household Internet use tends to be lowest amongst older Australians (65+) and in low income households, which suggests that lack of experience (with information communications technology) and financial resources are restricting household Internet uptake (Australian Bureau of Statistics 2014). Amongst businesses, lack of relevance or perceived need emerges as the main factor underlying the limited uptake of Internet enabled applications. However, cost (associated with establishing and maintaining a web presence), lack of customer demand and lack of technical expertise are also cited as factors (Australian Bureau of Statistics 2013, Lonergan Research 2013).

Economic analyses have been carried out to identify potential opportunities and risks associated with NGB in Australia. These find that the delivery of NGB in Australia will have a significant impact on the delivery of health and education and in the reduction of commuting enabled by videoconferencing (Budde 2013, Gans and King 2010, IBIS World 2012, Jayasundara 2011). In particular, regional communities are expected to benefit from NGB, given that through e-learning, telemedicine and other NGB-enabled initiatives, geographical distance becomes less of a barrier to accessing services. On the other hand, NGB may have negative impacts for some industry classes, e.g., traditional retailing, wholesale trade, traditional publishing and traditional entertainment media channels (IBIS World 2012). Analysts also warn that the benefits of NGB will not be achieved unless work is done to prepare Australian systems, individuals and organisations for it (Gans and King 2010).

Overall, while expert analyses identify important and pervasive opportunities associated with NGB in Australia, surveys of Australian householders and businesses suggest that uptake of NGB may be delayed or even limited if end-users do not understand what benefits they can gain from it, or do not have the skills and resources they need in order to engage with it effectively. The purpose of our research was to obtain input from wellinformed and high-level representatives from across Australian society and industry, to explore how NGB could change the way in which business is carried out (either positively or negatively), and what specific interventions and initiatives are needed to achieve the best possible outcomes from the investment in NGB infrastructure. 


\section{Engaging with NGB stakeholders in Australia}

To identify high-level stakeholders with expertise in both their own area and relating to NGB, we drew upon three sources of information: (a) advice from five subject matter experts (b) Internet searches and (c) government documents (Cromarty 2011, House of Representatives Standing Committee on Infrastructure and Communications 2011). From this input we developed a stakeholder map identifying seventeen stakeholder groups and 80 organisations from across Australian society and industry. We then went back to our subject matter experts to create a short-list of interview participants who provided representation from each of the stakeholder groups, were well-informed and connected in their own sector, and were also connected with information and communication technology developments and NGB in particular.

We emailed the forty-eight individuals on the short-list (and then followed up with a phone call), inviting them to take part in an interview to 'create a better understanding of the social and economic impact of next generation broadband in Australia'. Twenty-four (50\%) either elected to take part in an interview or nominated another person from their organisation to provide input. The sample included representatives from government (state, local and federal), information and communications technology, health, education, research, the legal sector, social services, manufacturing and regulatory groups and peak bodies representing consumers, small business and industry. The sample included chief executive officers $(n=4)$, chairpersons $(n=3)$, senior directors $(n=5)$, general managers $(n=2)$ and policy managers $(n=3)$. It was fairly balanced in terms of gender, with 13 male participants and 11 female participants. Approximately half of the participants described themselves as working in a role that gave them a strong or direct interest in NGB. For the other participants, NGB represented an important channel through which they would carry out their business in the future.

The interviews were carried out over the months of May, June and July 2013. All of the interviews were conducted over the telephone, by one of four interviewers, and typically lasted for 45 minutes. The interviews began with the interviewers introducing themselves and outlining the purpose of the research as follows:

I am one of the social scientists working on CSIRO's program of research exploring the opportunities and risks associated with the delivery of Next Generation Broadband in Australia - by which we mean a step change in the speed, quality and coverage of Internet access. We don't want to focus specifically on the National Broadband Network, we're looking more broadly at the potential impact of highspeed broadband if it were available to most Australian households and businesses. We seek your input, and that of other high-level stakeholders and thought leaders, to 
understand how these opportunities and risks may play out across the range of sectors and interest groups potentially affected by this new technology.

The interviews were semi-structured in that all participants were asked to respond to a set of key questions, with probing questions then used to clarify comments and elicit greater detail from participants. The key questions were:

1. How do you think business/ways of doing things in your area is likely to change with the introduction of next generation broadband?

2. What opportunities do you think next generation broadband will create in your sector/area?

3. Do you see potential for any risks in your sector with the introduction of next generation broadband?

4. What interventions or initiatives might be required to manage these opportunities and risks?

All of the interviews were recorded (with the participants' permission) and transcribed. Participants were given the opportunity to review any quotes taken from their interview prior to publication.

Interview transcripts were analysed in NVivo using a constant comparison analysis method (Leech and Onwuegbuzie 2007) - a common method of qualitative data analysis which identifies meaningful chunks of text and classifies them into themes. The coding process was guided by a 'start list' of codes that was generated by the four interviewers based on their experiences in the interviews. These start codes were structured according to whether responses represented opportunities, risks, interventions or research questions. Additional codes were included to capture information about participants' work roles and their interest in NGB. As the coding process progressed, new codes were added to the framework to capture emergent themes.

Initial coding was carried out by a research assistant (external to the research team) and two of the four interviewers. The coders met regularly to discuss their experiences and review changes to the coding framework so as to ensure that they were adopting a consistent approach. Subsequently, one of the researchers reviewed all of the coding to check for consistency.

Below, we describe the themes that emerged as participants discussed the changes, opportunities, risks and interventions associated with NGB in Australia. For each of the key questions, we identify commonly occurring themes, beginning with the themes that emerged most often across the interviews. As well as describing the way in which each theme was expressed across the interviews, we also provide representative quotes from the interviews to illustrate the themes in participants' own words. There was fairly strong consensus associated with these opportunities, risks and interventions but in those instances where a 
theme or idea only came out in interviews with participants from a certain sector or sectors, we provide this information.

\section{What opportunities will NGB create in Australia?}

We began the interviews by asking participants how they saw business or ways of doing things in their area changing with the introduction of NGB. This question was designed to be neutral, so that we could get a sense as to whether participants viewed NGB positively or negatively. All of the participants depicted NGB as bringing about positive change, although a few participants (representing social services, education and research) also identified some potential negative changes. Many participants (most commonly those representing business, education, government and the ICT sector) went further and predicted that the changes associated with NGB would be fundamental or transformative. Because 'anything that we do in our lives can be affected by high quality broadband', NGB would mean that 'our lives are enriched'. Some of the fundamental impacts that were suggested included 'enhanced democracy', 'being able to live and work where[ever] you want to live and work' and having technology 'take away some of the drudgery of life'. In the business context, participants described NGB as part of a 'digital revolution', which would transform markets by 'reducing the tyranny of distance', 'bringing producers and consumers closer together' and 'fundamentally transform[ing] services'.

The interview then delved into the specific opportunities that would be created in the stakeholders' area of business. First and foremost, NGB was expected to enhance the delivery of services, while also reducing the cost of doing business. Although these changes were expected to affect service delivery across all sectors, participants viewed NGB as having the greatest impact on the delivery of health, education and government services. The changes expected in each of these sectors are detailed below.

\section{Improvements to health services}

In the health sector, electronic health care records would improve diagnosis, create cost-savings and enhance patient care. Health care records and data would be stored online so that all health care providers would be able to quickly access a patient's online health records and review their medical history to inform their understanding of the patient's health care needs. Using videoconferencing and home-based sensors facilitated by NGB, it would be possible to deliver more health care services to patients in the home. One participant provided the following scenario:

...Mum's sitting there and the doctor says hi Mrs [X], can you step on the scales? She can get up and stand on a patch on the carpet and he can get an instant reading of her 
weight... And he can say that's good, can you put your hand on the pad on the chair and she can get her blood pressure taken, she can get her pulse taken. All the while he's observing her visually to see how she's reacting to his questions. She might have had - I don't know - some minor treatment for something that she's got a lesion or a wound; he can have a look at that at high definition. He can zoom in and he can say to her are you taking your tablets and she can say yeah, but I'm feeling a bit wonky in the afternoons...so these are just normal things that a doctor wants to do but the important thing there is that mum's not had to arrange transport, I haven't had to take the day off to go and take her to the doctor's... I know people as they get to that age, they're frail. The idea of a trip to the doctor's is a major excursion for them. [Interviewee 16]

\section{Improvements to education}

In the education sector, the ubiquitous availability of high speed broadband would allow educational institutions to establish partnerships that would give students access to global facilities and expertise from around the world, whilst reducing their own curriculum development and infrastructure costs. One participant gave the following example: ...part of our medical course is now taught by the University of California. They teach emergency medicine, in exchange for which, we teach anatomy using broadband. Now the more we do of this, the more universities will begin to specialise, ceding disciplines to one another, and running their operations more efficiently. And, as you would know probably, we can even run laboratory experiments over broadband, we can run experiments in laboratories in the United States after hours, without having to invest in that infrastructure here. [Interviewee 2]

Another participant from the education sector predicted:

...we will probably see things like hybrid situations where there will be some traditional learning within, maybe, formal settings or classrooms, but that will be complemented by an enormous amount of online learning. [Interviewee 12]

NGB would also change the way in which classes are run, creating more opportunities to experience external environments and engage with experts and people from other cultures. Workplace training would be able to be delivered in situ via new technology:

Devices like Google glasses...will allow someone in a factory and a remotely based trainer to interact and 'see' the same environment. Businesses see a lot of applications for that training, for example, an apprentice doesn't have to train offsite, they can be in their own factory developing skills and getting advice. [Interviewee 4] 


\section{Improvements to government service delivery}

More government services would be delivered online, offering greater convenience to the consumer at the same time as reducing the cost of service delivery. One area where NGB was seen to have high potential for impact was in the delivery of human services. One participant explained:

...if you're on the dole, there is a requirement that you be willing to travel up to 90 minutes a day for a job interview.... So if we were using the technology... you could conduct those interviews without having someone there face-to-face. I mean, similarly, the requirement that you attend Centrelink interviews every fortnight or every month, when often, people aren't seeing any progress in their capacity to get paid work, ... you're actually alleviating the burden of those requirements through broadband...

[Interviewee 15]

However, NGB would not only provide an alternative channel for the delivery of government services. It would also provide a channel for customers (or citizens) to communicate back to government, so that governments would have a better understanding of their electorates' needs and wants:

...I hope that broadband will enable citizens to be more engaged in participatory democracy, so a direct voice to elected representatives, a direct voice to ministers and to government because citizens can then express a view about what they want governments to invest in... if you were a government and you could say, 'You know what? Forty per cent of citizens are talking to us all the time and, of those 40 per cent of citizens, 89 per cent of them want health, education and social services, so that's what we're prioritising', so I think that - that's where I think it could - it could potentially go. [Interviewee 19]

\section{New ways of interacting and working together}

An important way in which NGB would change service delivery and other areas of work and home life was by transforming the Internet into a channel for rich communication and collaboration. As well as being able to interact via video-conferencing, and perhaps $3 \mathrm{D}$ video or holographic video, it would be possible for groups of individuals to work simultaneously on a single document or view the same images, equipment or data.

Improved online communication and collaboration would have important flow-on effects. Many participants predicted that telecommuting would become widespread and work arrangements would become more flexible. Not only would there be fewer people commuting to work, but less travel would be required in general. Online libraries would mitigate the need to travel to a library, home-based monitoring and health care 
appointments would reduce the need to travel to a doctor's surgery, online learning systems would replace travel to an educational facility, online income reporting would replace visits to a Centrelink office, and instead of travelling to a site, technicians would 'look' at equipment via optical head mounted displays to diagnose problems and instruct users as to how to repair it.

This ability to achieve rich interaction via the Internet would change some business models. One participant suggested:

So I think you'll see the potential for collaborations, and eventually even mergers and takeovers with other institutions. So, depending upon how all this goes, we could merge with the University of California, to become a new multi-national university called something or other, because our courses are integrated and co-taught, and we share staff, and infrastructure, and back office services. [Interviewee 2]

\section{Revitalising regional and remote Australia}

When discussing the opportunities associated with NGB, communities in regional and remote areas of Australia were often identified as key beneficiaries. The most significant benefit that was expected to occur for people in these communities was improved access to services. One participant described NGB as:

...fundamental to trying to create a more equitable service access model for remote communities. [Interviewee 23]

The ability to share data and consult with health specialists via the Internet would mean that health consumers would be able to save the time and costs associated with travelling to the city for these appointments. Friends and families in regional and remote areas would be able to have 'virtual visits' with patients in metropolitan hospitals. School and university students in remote areas would be able to see into museums and laboratories and ask questions of subject matter experts working in these locations.

Increased teleworking and the ability to connect with suppliers and customers via the Internet would also mean that more job and business opportunities would open up for employees and business owners in regional and rural Australia. Consequently, NGB was seen as a means of 'reinvigorating' regional and remote Australia, with one participant suggesting: ...internal migration in Australia has for a long period of time involved the movement of people from inland regional parts of Australia towards the coast and in particular towards the major capital cities. Broadband - next generation broadband has the potential to perhaps arrest that trend, indeed even reverse it. [Interviewee 21] 


\section{Expanding global and domestic markets}

The improved bandwidth and speed delivered by NGB was also seen as a conduit through which Australian businesses would be able to expand into global markets. One participant explained:

...broadband...removes the obstacle of distance, and it reduces the need to invest in infrastructure. If you think about what has shaped Australian history up until now, one major force has been the issue of distance. If you remove that obstacle, Australia can become a more competitive player in every industry... [Interviewee 2]

In consequence:

...developing products and services in Australia will be instantly transportable to anywhere else in the world. [Interviewee 16]

NGB was expected to facilitate exports in the agricultural and education sectors. More generally, NGB was expected to provide an opportunity to export high value services overseas:

Obviously we carry some relative challenges, in regard to the cost profile of our services industries internationally, and one of the most effective ways to mitigate and participate in the global... services economy is through smart use of the digital...to be much more productive and internationally competitive... there is a huge opportunity point right now over the coming years, in terms of high-value services provision to the growing Asian marketplace... a number of parts of that sector are hugely reliant on transfer of data... often domestically, but also increasingly internationally, and need to be confident that they can do so at fast speeds, and without barriers to success.

[Interviewee 10]

In addition, by increasing the number of Australians with high-speed Internet access, NGB would broaden the domestic markets available to small businesses.

\section{More data, better information}

NGB would also improve reporting and data capture systems and enable big data analysis. Wireless sensors and smart tablets would allow data to be collected from multiple sites and then brought together for analysis:

...new service industries are emerging based on analysis of data automatically collected from farm sensor networks and from machinery like harvesters. Under Precision Agriculture models, for example, service providers process data for farmers and send it back digitally in valued added forms. The digital economy can open up new farming practices and business models for agriculture and is key to future profitability. We see 
agriculture across all sectors moving into a more analytical realm with tighter control of inputs, yield and supply chain logistics. [Interviewee 1]

Online health records could provide population health data that would potentially offer new insights for medical research. Finally, the ability to bring complex data from multiple sources together would enable better business management:

For example, simply using a tablet a construction site enables photos of work to be taken, random spot checks of safety, and allows engineers to compare plans to actual work. Those kinds of practical applications have important productivity, quality and safety benefits for businesses. [Interviewee 4]

\section{What risks might arise from having NGB in Australia?}

After discussing the opportunities that NGB would create, participants were then asked: 'Do you see potential for any risks in your sector with the introduction of NGB?' Several participants (most often those representing the health sector) initially responded by saying that they did not think NGB would introduce any new risks, reinforcing the very positive attitudes that they had expressed regarding the opportunities offered by NGB. Nevertheless, subsequently, most participants went on to identify some issues of concern or potential risks, with representatives of business having the most to say on this topic. Below, we outline the risks that were commonly identified, beginning with concerns about Australia's lack of readiness for NGB, which was the topic that generated the most discussion across the interviews.

\section{Lack of readiness for NGB}

The risk of greatest concern to participants was that Australian businesses, government organisations and individuals would not be ready to take advantage of the opportunities offered by NGB. Participants cited a number of indicators of Australia's lack of readiness. One was the under-utilisation of current network capacity:

Within each state there is a massive amount of fibre available that is being underutilised, for example in universities, for example in hospitals, for example in schools, which loads of other services could have access to, and the community could have access to at speeds which are quite competitive with the NBN but nobody is commissioning that either. [Interviewee 13]

A second indicator of Australia's lack of readiness was the low uptake of those online government services that do exist:

So a lot of government services are moving online, but from the conversations that I have with people within government, they're not getting anything like the take-up that 
they anticipated, in terms of people using those services. So while those services may be more efficient, might offer more value to people...just because of this inherent inertia you're not able to achieve what you wanted to achieve in moving that service online.

[Interviewee 10]

A third indicator was the lack of preparation and thinking about digital innovation within Australian organisations. Participants were concerned that individuals and organisations were not aware of, or engaging with, the opportunities offered by NGB. The political debate associated with the plan for delivering NGB in Australia was seen to have contributed to a lack of engagement from government departments and businesses. Yet, participants warned, many businesses would need to develop new knowledge and skills and re-engineer their processes in order to remain competitive in a digital economy:

Australia is behind most of our competitors in using digital technology to streamline both government and business processes. Retaining, let alone gaining, global market share depends on us leveraging digital technology to become more efficient and agile. [Interviewee 1]

\section{Digital divide}

If many Australian organisations were not ready for NGB, still other groups were seen to be at risk of being left behind altogether. With fast and ubiquitous broadband more and more government, community, educational, social and business activities would be happening online. In an increasingly digital society and economy, anyone not able to access the Internet would risk missing out on important opportunities and experiences. The stakeholders that we spoke to identified three factors that would place people and organisations at risk: 1) lack of information technology skills and knowledge, 2) lack of financial resources, and 3) poor quality connections to the Internet. For example, individuals who had been unemployed for a long time or whose education was incomplete might not have the skills to participate in an increasingly technology-rich work environment. Some participants suggested that NGB would increase costs to individuals and businesses, by requiring more expensive Internet subscription plans, or new skills, equipment and technology to be acquired. These costs would have a disproportionate effect on low income households and small businesses. One participant explained:

...our constituents are individuals, families and households, many of whom are in poverty, and so any additional burden on their weekly purse is unsustainable... there are households in Australia that are impoverished and cannot sustain any increase in cost that is related to a key or an essential utility. [Interviewee 15] 
Similarly, if smaller organisations did not have the financial resources to engage with NGB on an equal basis with larger organisations, they might end up falling behind. One participant warned:

....if you start to see a significant difference in terms of the technological capacity of organisations to find out about... funding... just the capacity to put a submission in, is undermined, because you don't have the same bandwidth or the technology that you need to use that bandwidth. That would really exacerbate some of those competitive processes in a way that would be detrimental to smaller communities and certainly to smaller community organisations. [Interviewee 15]

Finally, given that fibre optic connections would not be rolled out to all geographic locations, participants were also concerned that people living in more remote areas (distant from wireless nodes) might not be able to utilise Internet-enabled technology in the same way as those with fibre optic connections. Thus, there was a risk that access to NGB could exacerbate existing disadvantages associated with lack of skills, education, financial resources or geography.

\section{Quality and delivery of the infrastructure}

Participants (especially those representing ICT, research and business) also expressed concerns about the infrastructure itself. First, they were concerned that the delivery of the infrastructure might not be uniform and ubiquitous. This was important because for businesses to invest in online services, they needed to know that:

... everyone's got broadband and it all meets these minimum standards. It's all got at least 25 megabytes per second.... upload sync speeds and download sync speeds are equivalent...The risks are that the technology adopted is not symmetric so that bandwidth in one direction isn't equivalent in the other direction, meaning things like high-resolution both-way video doesn't work as you'd like it to. [Interviewee 16] Some participants were concerned that the speed or capacity of the infrastructure would not be adequate for some of the technology that is currently being developed. Another concern was that the roll-out of the infrastructure was going to be too slow, or might never happen. Our participants were aware that other countries were developing their own national highspeed broadband networks and they were concerned that excessive delays in the delivery of infrastructure would leave Australia at a disadvantage when competing in the delivery of digital services and products.

\section{Loss of markets}

Interview participants also warned that NGB could lead to a loss of market share in some sectors. While access to overseas markets was identified as one of the opportunities 
associated with NGB, it would also create a conduit for overseas businesses to compete for Australia's domestic market. Low value services would be especially vulnerable to overseas competition. Participants also specifically identified the retail, entertainment and tertiary education sectors as areas that might suffer from increased trade exposure via the Internet. For example, the ability to stream entertainment content over the Internet was a potential threat for entertainment producers and broadcasters in Australia. One participant from the education sector was very concerned about the threat of overseas competition:

So we've now got this explosion of MOOCs [Massive Open Online Courses]...from the world's very finest universities: Harvard, MIT, and Stanford... there's a very real danger that the traditional Australian universities will... haemorrhage students to these open online courses if we don't come up with a competitor... so Harvard will continue to have its on-campus premium product, and then they'll conquer the rest of the world with their off-campus online offerings.... The moment they solve both of those issues - the credential issue, and the financial issue - if Australia is still doing then exactly what it's doing now, it'll be game over, I think, for most Australian universities. [Interviewee 2]

\section{Privacy and Security}

While online privacy and security risks were not seen to be unique to NGB, participants predicted that these risks might be exacerbated with the new technology, simply because more information would be accessible online:

... more and more people transacting, what I would call deeply personal information like their health records online ..., and more and more GPs doing that... the only heightened risk is the opportunists who will try to do things like steal identity, or bring about reputational risk or denial of service on those things which are being consumed greatly. Because you have got more happening, then there is more opportunity for those things to be intercepted, stolen.... [Interviewee 22]

A key message emerged from all the discussions on risks associated with NGB: delivering high quality and ubiquitous connections to the network was an important first step, but it was equally important to ensure that all business owners, employees and householders had the resources, knowledge, skills and motivation to make the best use of the infrastructure. Participants from across all the stakeholder groups were concerned that these elements were not yet in place. Fortunately, the interviews also provided an opening to explore their views on the types of actions that needed to be taken to achieve the best possible outcomes from NGB in Australia. 


\section{How should Australia prepare for NGB?}

Each participant was asked what (if any) initiatives and interventions were needed to manage the potential opportunities and risks associated with NGB in their sector. There was a strong call for government (mostly at the federal and state levels) to support uptake and utilisation of NGB, but also for other key stakeholders to work on building digital literacy and redesigning their business processes for NGB.

\section{Government action}

Participants called for government to provide greater certainty about the timing, capacity, reliability and coverage of Australia's NGB network. Without this clarity and confidence, businesses would not invest the time and resources required to transform their business processes so as to take advantage of the opportunities offered by NGB. However, some participants went further and suggested that the government needed to communicate how NGB would affect Australia's future social and economic outlook - outlining where the opportunities would exist to improve productivity, create jobs and grow market share and what research, program investments and skills development would be needed to ready Australia for these changes.

A second action for government was to review its own digital platforms and service delivery processes. Participants reported that NGB would provide the opportunity for government departments to achieve substantial cost savings, streamline service delivery and share information - but warned that these outcomes would not be realised unless a whole of government approach was taken towards integrating digital platforms. In addition, business models needed to be reviewed to take advantage of NGB:

...state governments need to have a policy review of how digital platforms, and particularly high speed broadband, will change the business models and service delivery of all the services for which they're responsible... I don't think that the state governments know that... you could deliver a dedicated education channel on the NBN platform. [Interviewee 13]

By using the NGB to transform government processes and service delivery, the government would also be acting as an early adopter or digital advocate, showcasing the benefits to be achieved from NGB. Several participants recommended that the government should also be actively educating householders and businesses about what the NGB had to offer and 'bring the community along' in what was essentially a national change process. One participant suggested that the government should deliver a national campaign to promote the benefits of NGB to a broader audience. Other participants recommended that the government should follow the example of South Korea by supporting the development of 
applications for householders that would stimulate demand for NGB. One participant from the health sector commented on the low uptake of telehealth services and initiatives by health care practitioners and suggested that government needed to provide incentives and funding (for training and hardware) to support practitioners to adopt these new ways of working. In the same vein, a representative from the education sector said:

...there's really this burden put on both university teaching staff and school teaching staff to start using these technologies, to start integrating them without really a whole lot of useful materials or support to do so. And I think it's a real worry when some teachers then therefore completely embrace that and some see it as a burden and I think you start to see major disparities in terms of the integration of technology into schools, and I think that's really a major issue and requires quite a big rethink. [Interviewee 24]

Finally, based on their concerns about the potential for digital divide, many participants recommended that the government should take action to ensure that all Australians had both the capability and the necessary resources (e.g., connection to the network and financial resources to cover the associated costs) to access and use NGB. As one participant put it:

...make sure that if we're going to invest in broadband, we also invest in building bridges with those locations and with those population groups so they don't get further left behind. [Interviewee 19]

Participants identified a number of ways through which the government could fulfil this responsibility. One suggested that access to the Internet should become a right, supported by regulation and policy. Delivering programs to promote digital literacy across the population (a recommendation discussed in more detail below) was seen as another means of addressing this issue. Representatives of community organisations also suggested providing financial compensation to low income households to cover the costs of hardware and connection to the NBN. No specific recommendations were made for groups that would not have fibre connections to the Internet, other than noting that 'compensating or mediating mechanisms' would need to be provided to ensure that these groups were not disadvantaged through having poorer quality connections to the Internet.

However, whilst most participants thought that the government needed to take action to ensure that NGB was utilised effectively, they also believed that other groups had a role to play in this process - both in building digital capability and in reviewing business processes to take advantage of NGB.

\section{Build digital literacy}

Since participants were concerned that Australian householders and businesses did not yet have the knowledge and skills to operate effectively in a digital economy and society, 
it followed that many recommended digital literacy interventions to address this deficit. However, their concern was not just that people should have the skills to do things online, but also that they understood the benefits of being online, and the ways in which NGBenabled applications could be utilised in their work and home lives. As mentioned earlier, when identifying actions for government, some participants recommended implementing a national digital awareness campaign. However, they also wanted to see other key stakeholders in this space (NBN Co, Telstra, local government and Mission Australia, peak organisations, Chambers of Commerce were all suggested) taking leadership. Each of these organisations could have their own digital inclusion campaigns to build enthusiasm and knowledge about the benefits of digital applications within their own consumer groups.

Apart from raising awareness of the benefits of NGB, there was also a need for educational and training programs to build digital capability. A challenge that emerged in these discussions was the need for a coordinated approach alongside the need to tailor digital literacy training to the needs and interests of different user groups. Current digital literacy initiatives in Australia were described as 'piecemeal,' 'a patchwork,' and 'tiny by comparison with the investment in NBN.' There was a call for evaluation of current digital literacy initiatives so as to identify what approaches are effective and for which groups.

Schools (and Universities, to a lesser extent) were identified as an important avenue through which use of the Internet and ICT-relevant capability could be promoted. However, alternative pathways were needed to reach other groups in the population, such as elderly people, people experiencing long-term unemployment, remote communities and people with a disability. Existing channels should be used to deliver digital literacy initiatives for these groups and training should focus on applications that were relevant to each group's specific needs and interests. Participants also recommended ensuring that everyone knew how to minimise privacy and security risks in an online environment and other principles of responsible Internet use.

Digital literacy training for businesses (particularly small to medium enterprises) was seen as a separate but equally important effort. Participants recommended that this group needed fast and efficient ways of learning about the opportunities to achieve efficiencies and grow their markets. Case studies and examples (ideally, examples from other organisations in the same sector) were suggested as an effective way of educating this group, since the formula for making best use of NGB was likely to vary according to contextual factors.

\section{Review of business processes}

Finally, participants argued that all organisations needed to begin reviewing their business processes to take advantage of NGB: 
...there really is a need to have a whole range of industry sectors think about research and engage in the implications of a step change in broadband for their businesses.

[Interviewee 6]

While this was an area for government leadership, participants warned that 'businesses need lead-in time for transformation' and that all businesses needed to start looking at how their services and processes could be re-designed around NGB. One participant illustrated this point by describing some of the issues that would have to be considered if parts of children's classroom learning were delivered into the home:

First of all, you've got to make it acceptable to the community... know that every...kid in the class is already sensitised to that different environment and.... it'll be acceptable... But then you say...have we got the infrastructure in place? Have we got the programs? Can we deliver a spelling lesson? Can we deliver the maths lesson... what do we have to do... teachers are generally not IT literate... give them the IT support. You can't have a school as we do in Australia where one of the dads comes in after work and helps set up the IT...when you're reliant on it for delivery, you've really got to resource it. So back to issues of resourcing, training IT, developing the software, developing the programs as an online delivery. [Interviewee 16]

\section{Conclusions}

Our study participants, all well-informed and well-connected individuals, representing multiple sectors of Australian society and industry, shared a very positive view of the opportunities offered by NGB. These ranged from improved services and revitalised regional and remote communities, to new business markets, better information, and cost savings. In contrast, the risks that were most commonly identified related to an inability or failure to engage with these opportunities, rather than anything inherently negative that would be precipitated by NGB. In part, this positive view of NGB may be a product of our research methods, since we sought input from representatives of stakeholder groups who were 'connected with information and communication technology developments and NGB in particular'. This expertise made their input valuable but it meant that we did not hear from individuals who were disengaged and perhaps more negative about NGB. Furthermore, not all of our target participants elected to take part in the research and it may be that the individuals who chose to participate had more positive attitudes towards NGB. While technological change is commonly viewed as a source of economic growth and advancement, it can also be understood as a source of social and economic disruption (Harris and Sarewitz 2012). However, our participants appeared to be conscious of this potential in that they were universally concerned about the need to ensure that Australian individuals and businesses would not be left behind as NGB was adopted both in Australia and internationally. 
The opportunities, risks and interventions that were identified and suggested by our study participants are consistent with those reported in the literature. Many of the participants that took part in our research would have been familiar with this literature, which may explain this consistency. However, as we argued at the outset of this study, this international literature cannot provide good insight into the specific opportunities and risks that NGB will offer in Australia's unique social, economic and environmental context. For this reason, we sought to identify the social, economic and environmental factors that are likely to influence the way in which NGB plays out in Australia.

One of the factors that emerged from these interviews was the low level of awareness and readiness for NGB across communities, businesses and government. Second, there was seen to be high risk of digital divide in Australia, due to the difficulty of providing fibre connections to communities in remote areas, the predominance of small businesses in the economy and the relatively high cost of hardware and Internet connections in Australia. Low income households and smaller businesses might not have the resources to access and utilise NGB and more remote communities might not have the same online experience as the rest of Australia. Finally, considering the relatively high cost of labour in Australia and Australia's geographic proximity to the growing Asian economies, high-value services were seen to be an area of competitive advantage under NGB.

All of these factors were reflected in the recommendations that participants gave when outlining potential interventions and initiatives that would ensure the best utilisation of NGB infrastructure. These recommendations centred around the need for government action, the need to build the nation's digital capability, and the need to begin transforming business processes to take advantage of NGB. Perhaps more implicit than explicit in these recommendations was the need for a point of leadership for the national NGB change effort. While there are many groups with a responsibility or interest in ensuring that NGB is utilised effectively, there was no one agency or individual point with ultimate responsibility for driving this process - for example, no one agency with clear oversight and responsibility for coordinating digital literacy programs, promoting digital inclusion, initiating a whole of government business processes review, collating and sharing examples of best practice, or allocating funding and resources to support the development and uptake of NGB-enabled applications. However, the many comments about the need for leadership, coordination of effort and a more strategic approach in these areas suggest that there would be value in having a single point of contact for these efforts. Furthermore, lack of coordination and duplication of effort has also been identified as a problem in the implementation of the NBN and digital literacy initiatives at early release sites (Bowles 2013).

The specific actions suggested by our participants to manage the outcomes associated with NGB in Australia are also supported by other research. Prior research illustrating that 
Australian businesses are not sure of the benefits of NGB and are using the Internet in a limited manner (Australian Bureau of Statistics 2013, Lonergan Research 2013) supports the need to communicate the benefits of NGB and build digital literacy. However, implementing this recommendation is not straightforward. Back in 2009, the Australian Government reported that it was funding initiatives to support digital inclusion across Australian communities. Nevertheless, four years later our research participants report that more effort needs to be directed towards raising digital literacy. Efforts to build digital literacy and support digital inclusion in the United Kingdom have had similar effects. The UK Online initiative sponsored community Internet access points, free Internet training and major campaigns to promote awareness to targeted groups. However, an evaluation conducted by the National Audit Office (The Comptroller and Auditor General 2003) found 'limited signs' that older people were taking advantage of these initiatives. Before funding more digital literacy interventions, it would seem desirable to invest effort towards identifying what types of interventions are effective.

In closing, we must acknowledge that it is difficult to do justice to the range of input that the participants in this research offered. We have drawn out ideas and themes that emerged across the interviews and that have broad applicability. However, since we only spoke to a few representatives from each stakeholder group, this approach sometimes obscured very specific issues relating to a particular sector. Nevertheless, we believe this paper conveys the way in which informed stakeholders described the key opportunities, risks and recommendations associated with NGB playing out across the different sectors of Australian society and industry. As with other disruptive technologies, it will be the capacity of people and organisations to respond in a timely way to opportunities and threats created by next generation broadband that will largely determine the level of benefits that might accrue to Australia. The insights offered by our research participants serve to inform this effort.

\section{Acknowledgements}

The authors thank the research participants for giving their time and expertise to inform this research. We also appreciate the guidance and advice that we received from Colin Griffith in his role as Director of the Australian Centre for Broadband Innovation. Further information about CSIRO's program of research exploring social and economic impacts associated with NGB is available from: http://www.csiro.au/Organisation- 
Structure/Flagships/Digital-Productivity-and-Services-Flagship/ACBI-Broadband-Impacts-

Report.aspx

\section{References}

Aizu, Izumi. 2002. "A comparative study of broadband in Asia: Deployment and policy. Tokyo, Japan: Asia Network Research. http://www.rieti.go.jp/jp/events/02042201/pdf/aizu 1.pdf.

Australian Bureau of Statistics. 2013. Business Use of Information Technology, 2011-12.

Australian Bureau of Statistics. 2014. "Household Use of Information Technology, Australia, 2012-13: Australian Bureau of Statistics.

http://www.abs.gov.au/ausstats/abs@.nsf/Latestproducts/8146.oMedia

\%20Release12012-13?

opendocument\&tabname $=$ Summary $\&$ prodno $=8146.0 \&$ issue $=2012-$ 13\&num $=$ \&view=.

Bauer, Johannes M., Ping Gai, Junghyun Kim, Thomas A. Muth, and Steven S. Wildman. 2002. "Broadband: Benefits and policy challenges. East Lansing, MI: Quello Center, Michigan State University. http://citeseerx.ist.psu.edu/viewdoc/download? doi=10.1.1.110.4171\&rep=rep1\&type $=$ pdf.

Baum, J. Robert, Edwin A. Locke, and Shelley A. Kirkpatrick. 1998. "A longitudinal study of the relation of vision and vision communication to venture growth in entrepreneurial firms." Journal of Applied Psychology no. 83:43-54.

Beard, T. Randolph, George S. Ford, Lawrence J. Spiwak, and Michael Stern. 2010. "The broadband adoption index: Improving measurements and comparisons of broadband deployment and adoption." Federal Communications Law Journal no. 62 (2):Article 4.

Benkler, Yochai, Robert Faris, Urs Gasser, Laura Myakawa, Stephen Schultze, Jerome Baudry, Lee Baker, Eliane Bucher, Anjali Dalal, Gildas de Muizon, Jan Gerlach, Jock Given, Andrew Goodman, Hank Greenberg, Pascal Herzog, James Kwok, Alan Lenarcic, Parina Patel, Debbie Rosenbaum, Tarek Saghir, Olivier Sautel, Marta Stryszowska, Lara Srivastava, Andrea Von Kaenel, and Asa Wilks. 2010. Next generation connectivity: A review of broadband internet transitions and policy from around the world. edited by The Berkman Center for Internet and Society at Harvard University.

Bowles, Marcus. 2013. "The critical role of e-skills in raising NBN adoption and Australia's competitiveness in the global Digital Economy." Telecommunications Journal of Australia no. 63 (1):10.1 - 10.17.

Budde, Paul. 2013. "The UN Broadband Commission for Digital Development." Telecommunications Journal of Australia no. 63 (1):5.1-5.8.

Cromarty, Jennifer. 2011. "Gippsland broadband engagement plan: Connecting communities. Melbourne, VIC: Socom Pty Ltd. http://gippslandregionalplan.com.au/media/Broadband Engagement Plan.pdf.

Frieden, Rob. 2005. "Lessons from broadband development in Canada, Japan, Korea and the United States." Telecommunications Policy no. 29:595-613.

Gans, Joshua S., and Stephen P. King. 2010. "'Big bang' telecommunications reform." The Australian Economic Review no. 43:179-186.

Harris, Paul, and Daniel Sarewitz. 2012. "Destructive creation and the new world disorder." Current History no. 111 (741):29-33.

Helsper, Ellen, William Dutton, and Monica Gerber. 2008. To be a network society: A crossnational perspective on the internet in Britain. Oxford, UK: Oxford Internet Institute.

House of Representatives Standing Committee on Infrastructure and Communications. 2011. Broadening the debate: Inquiry into the role and potential of the National Broadband 
Network. edited by House of Representatives Standing Committee on Infrastructure and Communications. Canberra, ACT: The Parliament of the Commonwealth of Australia.

IBIS World. 2012. A snapshot of Australia's digital future to 2050. IBIS World.

INSEAD, and World Economic Forum. 2013. "The Global Information Technology Report 2013: Growth and jobs in a hyperconnected world, ed Benat Bilbao-Osorio, Soumitra Dutta and Bruno Lanvin. Geneva, Switzerland: World Economic Forum and INSEAD.

International Telecommunication Union. 2013a. "Measuring the Information Society. Geneva, Switzerland: International Telecommunication Union. http://www.itu.int/en/ITU-D/Statistics/Pages/publications/mis2013.aspx.

International Telecommunication Union. 2013b. World Telecommunication/ICT Indicators Database. Geneva, Switzerland: International Telecommunication Union.

Jakopin, Nejc M., and Andreas Klein. 2011. "Determinants of broadband internet access take-up: Country level drivers." info no. 13 (5):29-47.

Jayasundara, Nadeen. 2011. "Australia's digital economy @ 100MBPS and beyond: The potential social and economic benefits from a next generation national broadband network infrastructure." Telecommunications Journal of Australia no. 61 (3):50.150.26 .

Katz, Raul. 2012. "The impact of broadband on the economy: Research to date and policy issues, ed International Telecommunication Union. Geneva, Switzerland:

International Telecommunication Union. https://www.itu.int/ITUD/treg/publications/bbreports.html.

Lau, T. Y., Si Wook Kim, and David Atkin. 2005. "An examination of factors contributing to South Korea's global leadership in broadband adoption." Telematics and Informatics no. 22:349-359.

Lee, Choongok, and Sylvia M. Chan-Olmsted. 2004. "Competitive advantage of broadband Internet: A comparative study between South Korea and the United States." Telecommunications Policy no. 28:649-677.

Leech, N. L., and A. J. Onwuegbuzie. 2007. "An array of qualitative data analysis tools: A call for qualitative data analysis triangulation." School Psychology Quarterly no. 22:557584. doi: http://psycnet.apa.org/doi/10.1037/1045-3830.22.4.557.

Lonergan Research. 2013. "Digital literacy report: Lonergan Research.

Middleton, Catherine, Sora Park, and Matthew Allen. 2013. "Converging on an NBN future: Content, connectivity, and control - symposium overview." Telecommunications Journal of Australia no. 63 (1):8.1-8.8.

National Broadband Task Force. 2001. "The new national dream: Networking the nation for broadband access. Ottawa ON: Industry Canada. http://publications.gc.ca/collections/Collection/C2-574-2001E.pdf.

OECD. 2013. OECD Communications Outlook 2013: OECD Publishing.

The Comptroller and Auditor General. Progress in making e-services accessible to allencouraging use by older people. National Audit Office 2003 [cited 26 March 2014. Available from http://www.nao.org.uk/wpcontent/uploads/2003/02/0203428es.pdf.

World Bank. 2013. "The Little Data Book on Information and Communication Technology 2013. Washington DC: World Bank.

\section{Cite this article as:}

Claire Mason, Beth O’Brien-McInally, Sharon Dane. 2014. High-level stakeholders’insights on readying Australia for Next Generation Broadband. Australian Journal of Telecommunications and the Digital Economy, Vol 2, No 2, Article 39. http://doi.org/10.7790/ajtde.v2n2.39. Published by Telecommunications Association Inc. ABN 34732 327 053. http://telsoc.org 